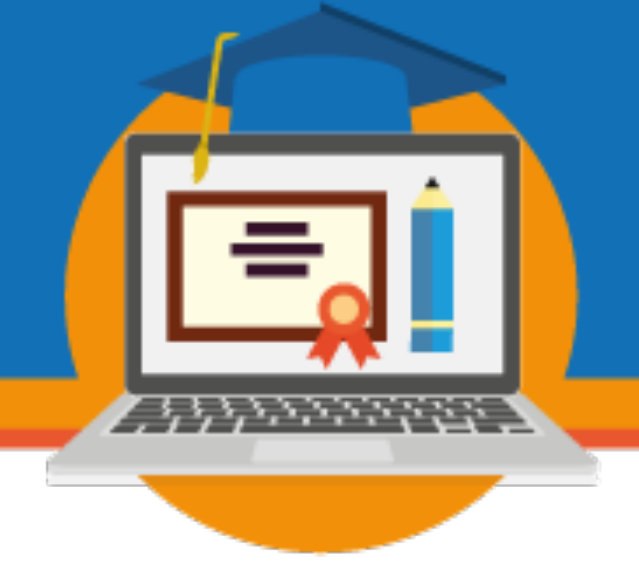

\title{
UMA PERSPECTIVA DE FORMAÇÃO CONTINUADA NA GESTÃO ESCOLAR
}

\author{
Keyla Maria Bastos Gonçalves Silva \\ Secretaria Municipal de Educação de Anápolis \\ keylambgcandeia@gmail.com \\ Kátia Cilene Camargo Silva \\ Faculdade Católica de Anápolis \\ kccs67@hotmail.com \\ Itair Regina Carvalho Diogo \\ Secretaria Municipal de Educação de Anápolis \\ recarvalhodiogo@hotmail.com
}

Eixo 06: Tecnologias e mediações pedagógicas

Resumo: As mudanças sociais ocorridas em virtude dos avanços científicos e tecnológicos impactam diretamente na instituição escolar em sua forma organizacional e nas relações estabelecidas entre seus pares. Emerge a necessidade da figura de um diretor que apresente qualificações necessárias para gerir este novo cenário escolar. Contudo, é preciso uma reflexão acerca de que formação tem sido propiciada ao diretor e qual estrutura organizacional e os meios utilizados para proporcionar esta formação, presencial, semipresencial e em EAD. Analisa-se a proposta de formação continuada de gestores escolares em curso, utilizando-se da revisão sistemática do projeto do curso, acompanhamento da ação gestora, avaliação final e necessidade de reestruturação em sua modalidade.

Palavras-chave: formação continuada; gestores escolares; modalidade de ensino.

Formação continuada dos gestores escolares - uma necessidade, um desafio para os sistemas de ensino

A qualidade da educação é relacionada tradicionalmente ao resultado dos estudantes nos testes avaliativos de conteúdo padronizado, universalmente tornados obrigatórios pelos organismos nacionais e internacionais que direcionam os debates e a compreensão do fenômeno educacional. 


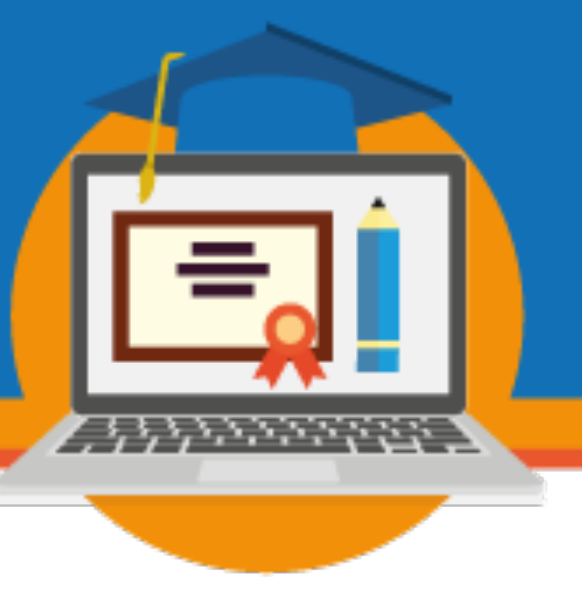

Toda discussão gerada em torno desse nebuloso conceito de qualidade tem reforçado a compreensão tradicional do papel salvador da escola, tida pelo "senso comum" como única ou "melhor" escada de ascensão social, levando a desvios de foco no debate sobre os caminhos das políticas educacionais e das escolhas a elas subjacentes acerca do papel social da educação e da escola.

Neste contexto, a elevação do rendimento da aprendizagem na rede escolar pública se tornou um dos elementos centrais perseguidos pelas políticas de educação nas últimas décadas, tendo o gestor como o maestro da condução de um processo de ensino-aprendizagem eficiente.

Não pactuando com este conceito de qualidade que vem se afirmando na atualidade, percebe-se a gestão escolar como uma dimensão importantíssima da educação, uma vez que, por meio dela, observa-se a escola e os problemas educacionais de modo global, para que se possam buscar ações interligadas que venham melhorar sua atuação e resolver ou minimizar os referidos problemas.

A gestão é um meio e não um fim em si mesmo. Uma vez que o seu objetivo final deve ser a aprendizagem efetiva e significativa dos estudantes, de modo que, no cotidiano que vivenciam na escola, desenvolvam os saberes que a sociedade demanda.

O processo de gestão escolar deve estar voltado para garantir a qualidade social ' do ensino oferecido, devendo assim buscar estruturas e condições adequadas ao desenvolvimento do trabalho docente, ampliação da compreensão das diferentes relações que permeiam a organização da ação educativa e a transmissão e reelaboração significativa dos conhecimentos.

Libaneo (2001) nos chama a atenção para o fato de que é necessário que haja qualidade sim, no entanto, diferente daquela concepção, e se refere à qualidade social na escola, isto é, significa a inter-relação entre qualidade formal (instrumentos, procedimentos, conhecimento) e

${ }^{1}$ Para Libaneo é aquela que promove para todo o domínio de conhecimentos e o desenvolvimento de capacidades cognitivas, operativas e sociais necessários ao atendimento de necessidades individuais e sociais dos alunos, à inserção no mundo do trabalho, a constituição da cidadania, tendo em vista a construção de uma sociedade mais justa e igualitária.

\section{SEMINÁRIO DE EDUCAÇÃO A DISTÂNCIA}

Diálogos sobre EaD e uso das TDIC na educação: regulamentação em tempos recentes 3 a 6 de novembro de 2020 - Brasília/DF - Online 
política (fins e valores sociais), é baseada no conhecimento e na ampliação de capacidades cognitivas, operativas e sociais, com alto grau de exclusividade.

Para que a escola possa efetivamente contribuir para a construção da cidadania, por meio da apropriação significativa dos conhecimentos historicamente constituídos, superando os processos administrativos centralizados e fundamentados em decisões de natureza técnica e burocrática, constitui em um desafio a ser enfrentado pela escola e fundamental para que se possa pensar a organização de processos educativos com vistas ao bem comum e à construção da cidadania.

Diante dessa evolução nos processos de gestão escolar, acredita-se na importância de se buscar a reflexão formativa da comunidade escolar, em quaisquer de suas dimensões: pedagógica, administrativa e financeira. Nesse intento a formação continuada é um instrumento que possibilita acompanhamento pedagógico mais preciso, potencializando a produção de conhecimento e de gestão refletindo positivamente no aluno.

A gestão escolar tornou-se foco de discussão em todos os níveis dos sistemas de ensino brasileiro por acreditar ser este o grande mecanismo de melhoria da qualidade e desenvolvimento da organização educacional. Outra questão de suma importância é o papel que deve ser desempenhado pelos gestores para que o processo democrático e autônomo seja parte da qualidade e do desenvolvimento educacional nestas instituições de ensino.

A perspectiva para uma gestão democrática implica necessariamente que todos os envolvidos com a instituição de ensino participem da elaboração e da execução dos planejamentos da escola. A gestão democrática passa pela ótica articulada das ações para a realização conjunta das propostas e necessidades educacionais de uma determinada comunidade escolar.

Esta associação à tomada de decisões no interior da escola propõe a presença de uma gestão democrática participativa que:

(...) baseia-se na relação entre a direção e a participação dos membros da equipe. Acentua a importância dos membros da equipe. Acentua a importância da busca de objetivos comuns assumidos a todos. Defende uma forma coletiva de tomada de decisões. (LIBANEO; OLIVEIRA; TOSCHI, 2012, p.447). 
Neste sentido, analisando situações, decidindo sobre o seu encaminhamento e agindo sobre elas em conjunto, desse trabalho compartilhado, orientado por uma vontade coletiva, criase um processo de construção de uma escola competente, compromissada com a sociedade (LUCK, 2000. p. 27).

A construção do processo democrático de gestão pública nas escolas insere-se no contexto da educação brasileira a partir de 1996, com a Criação da Lei de Diretrizes e Bases da Educação Nacional, Lei no. 9.394/96 que no seu Art. 15, afirma que "Os sistemas de ensino assegurarão às escolas públicas de educação básica que os integram progressivos graus de autonomia pedagógica e administrativa e da gestão financeira observada às normas gerais do direito financeiro público"

Nessa ótica, a autonomia da gestão passa pela necessidade de uma autogestão financeira; da descentralização do poder e da democratização do ensino, cujas bases são fortalecidas quando o diretor escolar concebe o significado da autonomia da gestão escolar, assim Luck, (2006) enfatiza que "(...) para muitos diretores de escola, a autonomia corresponde à capacidade de agir independentemente do sistema" (p. 63-64).

A formação dos diretores escolares se torna nesse contexto ação fundamental na implementação e ressignificação do ideário de gestão educacional, faz-se necessário ter clareza sobre quais serão os objetivos, valores e metas que delinearão, sob o olhar do gestor, a comunidade escolar. Sendo assim, não se pode aceitar mais que os gestores de escolas públicas aprendam pelo ensaio e erro, mas pelo processo de formação tanto inicial e continuada, pois, "A responsabilidade educacional exige profissionalismo" (LUCK, 2000, p. 29).

Apenas reconhecer que a formação inicial do docente apresenta lacunas e que o contexto escolar é permeado por situações complexas exigindo que o profissional pense e execute ações assertivas, não resolve o problema, é necessário criar um espaço para promoção do diálogo, da pesquisa, e da formação continuada, possibilitando assim a melhoria de sua prática.

Nesta perspectiva, o professor que assume a gestão escolar também deve ter o direito à formação continuada, pois na maioria das vezes sai da sala de aula para assumir a função para qual foi eleito democraticamente, sem ter a ideia da dimensão e da abrangência de ser 
atualmente gestor de uma escola que em sua essência deve ser democrática e de qualidade social.

A formação continuada visa ao aperfeiçoamento profissional teórico e prático no próprio contexto de trabalho, e ao desenvolvimento de uma cultura geral mais ampla. Diante da afirmação compreende-se a formação continuada como possibilidade de proporcionar aos professores gestores um processo constante do aprender a profissão, não como resultado de amontoado de informações, mas como um momento de repensar as suas práticas e construir novos conhecimentos que se formam por meio de estudo, da reflexão, da discussão e da confrontação de diferentes experiências profissionais.

O necessário é que o foco principal das instituições escolares seja a aprendizagem dos alunos, para isso é preciso que o gestor supere as questões administrativas e adentre as questões pedagógicas, conforme afirma Luck (2006) que a concepção de gestão supera a administração e não a substitui. A autora indica que a ideia de gestão traz uma mudança paradigmática que se desenvolve associada a outras ideias globalizantes e dinâmicas em educação, ideias como sua dimensão política e social, ação para a transformação, participação, práxis, cidadania, autonomia, interdisciplinaridade, avaliação qualitativa, entre outras que influenciam todos os aspectos da educação que devem ser abordados durante o processo de formação continuada.

Vale Importante destacar que a gestão administrativa precisa estar a serviço da gestão pedagógica, é preciso entender que a gestão acontece com o coletivo, e que de acordo com Paro (2000), a administração geral pode ser vista, tanto na teoria quanto na prática, como dois campos que se interpenetram, a racionalização do trabalho e a coordenação, levando em conta respectivamente, os elementos materiais e conceptuais, de um lado, e o esforço humano e do outro o esforço coletivo.

A discussão em relação a ampliação do conceito de gestão escolar é abordado e garantido na Lei de Diretrizes e Bases de 1996, o que não está claro são as especificidades e responsabilidades que a ação gestora precisa desempenhar. Em seu art. 12 incisos de I a VII atribuem ao professor gestor as ações de:

\section{SEMINÁRIO DE EDUCAÇÃO A DISTÂNCIA}




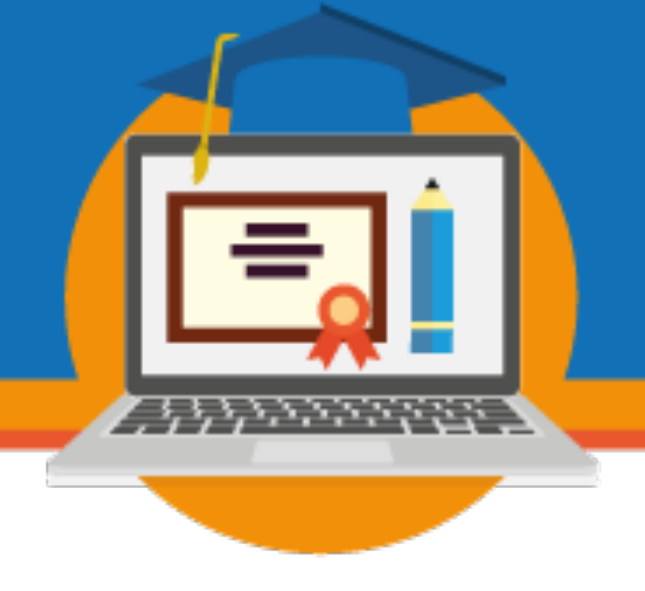

[...] elaborar e executar sua proposta pedagógica; administrar seu pessoal e seus recursos materiais e financeiros; assegurar o cumprimento dos dias letivos e das horas-aula estabelecidas legalmente; velar pelo cumprimento do plano de trabalho de cada docente; prover meios para a recuperação de alunos de menor rendimento; articular-se com as famílias e a comunidade, criando processos de integração da sociedade com a escola; informar pais ou responsáveis sobre a frequência e o rendimento dos alunos, bem como sobre a execução de sua proposta pedagógica.

Percebe-se que o movimento pela ampliação da abrangência das competências do gestor exige maior habilidade na gestão, evidenciando que a formação continuada passa a ser uma necessidade e um desafio para os sistemas de ensino.

Nesse sentido, a Secretaria Municipal de Educação de Anápolis no seu planejamento estratégico e educacional de gestão, tem avançado no entendimento que a qualidade da educação se expressa na efetiva aprendizagem dos alunos, decorrendo de uma política educacional voltada para a construção de um espaço onde todos tenham as mesmas oportunidades. Nesse caminho, a busca pelo fortalecimento das lideranças nas escolas ganha sua adequada dimensão, o que reforça, por parte da Secretaria, institucionalizar uma formação continuada para os gestores.

A ação formativa para as lideranças das instituições escolares da rede pública de Anápolis propõem refletir justamente sobre esta questão. Garantia da formação administrativa e pedagógica para a atuação nas instituições escolares, pois como afirma Libaneo (2004), Luck (2003) dentre outros, a gestão educacional hoje tem dois princípios fundamentais, que não são excludentes, mas complementares: a democratização da gestão escolar e a profissionalização da ação diretiva. É justamente este foco, que pretendemos refletir, pesquisar e analisar neste artigo.

Conforme os aspectos mencionados, propende a escrita de o artigo sociabilizar a experiência da formação continuada do gestor da Rede Municipal de Ensino de Anápolis.

\section{Condução de um processo de ensino-aprendizagem - Curso: O papel da gestão escolar nos processos educativos.}




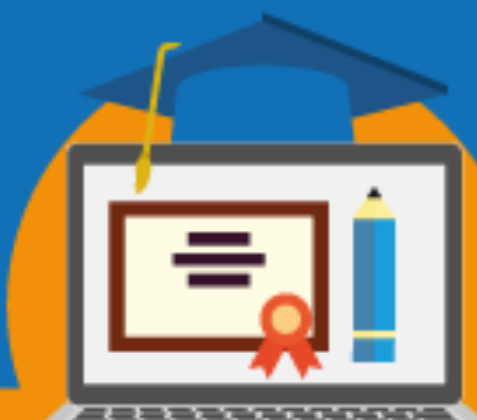

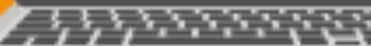
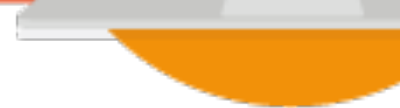

O processo de formação continuada como princípio amparado teoricamente e alimentado por práticas de gestão eficiente oferece subsídios que compõem ações para enfrentamentos dos desafios da gestão escolar em face das demandas que a escola enfrenta em seu cotidiano.

A formação continuada para todos os gestores das unidades escolares da Rede Municipal de Educação de Anápolis vem ocorrendo de forma sistemática desde 2009, com formato de parceria com as instituições de ensino superior e em períodos de curta duração apenas no início de cada mandato.

Ocorre que, através da exposição dos cursistas e da análise das avaliações, percebeu-se a necessidade de organizar uma formação continuada que se desse ao longo de todo o mandato e que atendesse as especificidades da função agora em exercício. Neste entendimento, no mandato correspondente ao biênio 2014/2015, a Secretaria Municipal de Educação (SEMED) por meio do Centro de Formação dos Profissionais em Educação² (CEFOPE) elabora e organiza o projeto de curso buscando atender as reivindicações expostas pelos cursistas, cujo objetivo é de proporcionar aos diretores-das instituições escolares, conhecimentos a respeito da gestão dos processos educativos, democráticos e financeiros próprios da atividade que irão desempenhar, relacionando tais conhecimentos à realidade da educação municipal, compreendendo o papel social da escola pública na formação do cidadão.

O curso, o papel da gestão escolar nos processos educativos teve como objetivo possibilitar a reflexão teórica e metodológica acerca da função do diretor. Organizado na modalidade presencial, e com formação inicial com duração de dois dias para apresentação do curso, análise da situação educacional da rede municipal e conceituação da Gestão Escolar e formação continuada ao longo dos anos de 2014/2015 com encontros mensais, abordando a

${ }^{2}$ CEFOPE - Centro de Formação dos Profissionais em Educação, departamento responsável pela elaboração da política de formação continuada dos professores e servidores da educação básica do município de Anápolis. 


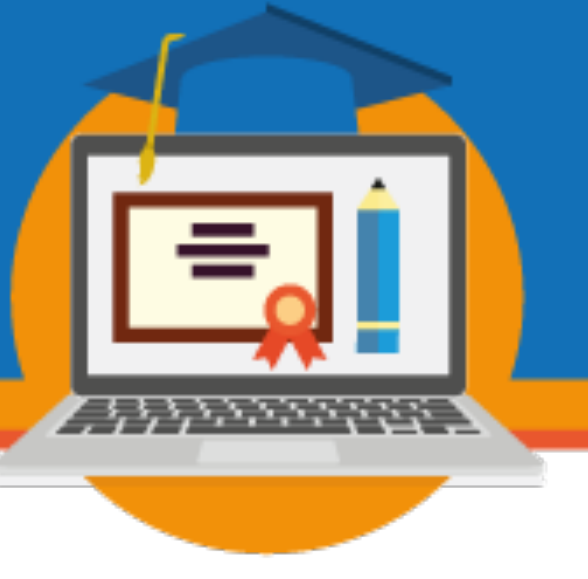

Gestão dos Processos Educativos, Gestão Burocrática e Gestão dos Recursos Financeiros da Escola.

A análise da realidade educacional do país, do estado, do município e das escolas, foi o foco das reflexões, dos debates, das proposições e das decisões que participaram desse momento. O papel de manter viva essa referência coube em grande parte ao formador do curso.

No decorrer da formação surgiram discussões que exigiram o envolvimento de outros segmentos da Secretaria Municipal de Educação e/ou Instituições de Ensino Superior, assim, como a participação dos gestores e/ou comunidade escolar nos cursos do programa Formação pela Escola, desenvolvido pelo FNDE - Fundo Nacional de Desenvolvimento da Educação.

Os encontros de Formação Continuada foram desenvolvidos de forma expositiva dialogada, com o suporte de textos, artigos de jornais e revistas, slides, filmes e livros didáticos.

A participação foi incentivada por meio dos seguintes procedimentos didáticos: estudos e análises de textos, leitura orientada de forma que os participantes demonstrassem compreensão e o estabelecimento de relações entre a leitura, o conteúdo proposto e a realidade vivenciada no cotidiano das unidades escolares.

Os estudos propostos desencadearam análise dos dados das escolas (metas estabelecidas no Projeto Político Pedagógico, Diagnósticos de alfabetização, Relatórios descritivos, Fichas de acompanhamento do desenvolvimento de habilidades, Desempenho acadêmico, Frequência de alunos e professores, observações e orientações das Assessorias Pedagógicas, IDEB - Índice de Desenvolvimento da Educação Básica, resultados das avaliações institucionais e externas) e outros aspectos importantes relativos à gestão escolar, que proporcionaram discussões e reflexões sobre a própria prática, influindo em uma gestão que contribua para a aprendizagem de todos os alunos.

O Curso foi organizado com carga horária de 96 horas presenciais, com 24 encontros de 04 horas. Os encontros aconteceram no horário de trabalho dos diretores uma vez ao mês, com discussão dos seguintes conteúdos: Gestão Escolar e Liderança Educacional, Legislação e Políticas Educacionais, A Educação Escolar Pública e Democrática no Contexto Atual, Os 
Programas do Fundo Nacional de Desenvolvimento da Educação, Subsídios Teóricos para o Entendimento do Processo de Gestão dos Processos Educativos, Princípios Básicos da Administração e Gestão Escolar, As Áreas de Atuação da Organização e da Gestão Escolar para Melhor Aprendizagem dos Alunos, Princípios Básicos da Administração Pública: Legalidade, Moralidade, Impessoalidade e Publicidade, Constituição dos Conselhos Escolares e Papel desses Conselhos. Planejamento Estratégico, Execução e Prestação de Contas, Financiamento da Educação Escolar.

Os cursistas para serem considerados aprovados no curso eram necessários que obtivessem frequência igual ou superior de $75 \%$ (setenta e cinco por cento) das horas ministradas e que realizassem todas as atividades propostas durante o curso com aproveitamento igual ou superior a 7,0 (sete). A realização do curso era condição para a permanência na função e o não cumprimento de um dos itens relacionados acima implicava na reprovação, inviabilizando futura candidatura.

No processo de avaliação, as atividades de Práticas de Gestão (PG) foram de suma importância, pois exigia dos gestores um nível de aprofundamento teórico, objetividade, criatividade e uma análise crítica relacionando os assuntos abordados e as especificidades da ação gestora, bem como os impactos sobre sua prática. Ao término da formação foi proposto um Seminário, que oportunizou aos gestores o relato de experiências exitosas.

Os recursos para a realização do curso foram da própria Secretaria Municipal de Educação, sob a forma de pagamento de proventos das professoras/formadoras, da equipe de apoio, provimento de material de limpeza, higiene e manutenção das condições físicas do local.

Ao término do curso realizou-se a avaliação final. A partir desta avaliação, foi possível perceber avanços dos objetivos propostos no curso. Evidenciou-se, a mobilização para a construção de conceitos com respaldo em uma formação profissional contínua dentro da realidade na qual os professores, agora diretores, estão inseridos. 


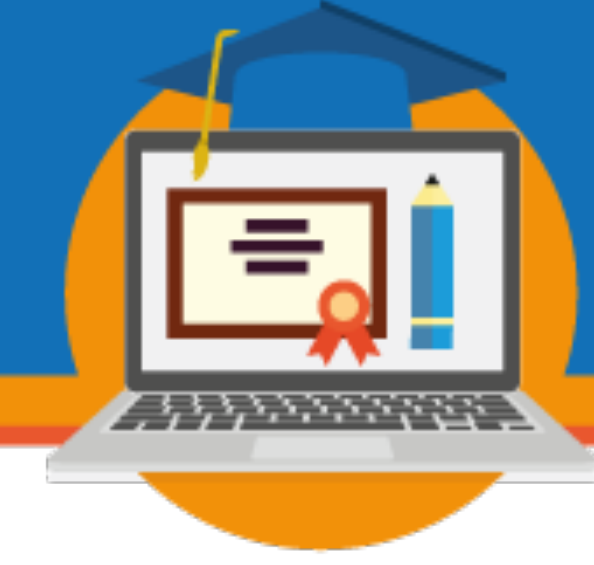

Os diretores vivenciaram no cotidiano da instituição os enfrentamentos na gestão dos processos de ensino e aprendizagem com mais amadurecimento teórico e profissional, relatando que o curso os ajudou a reavaliar seus saberes e práticas.

Avalição Curso de Diretores - Biênio 2014-2015 - \% -Gráfico 1

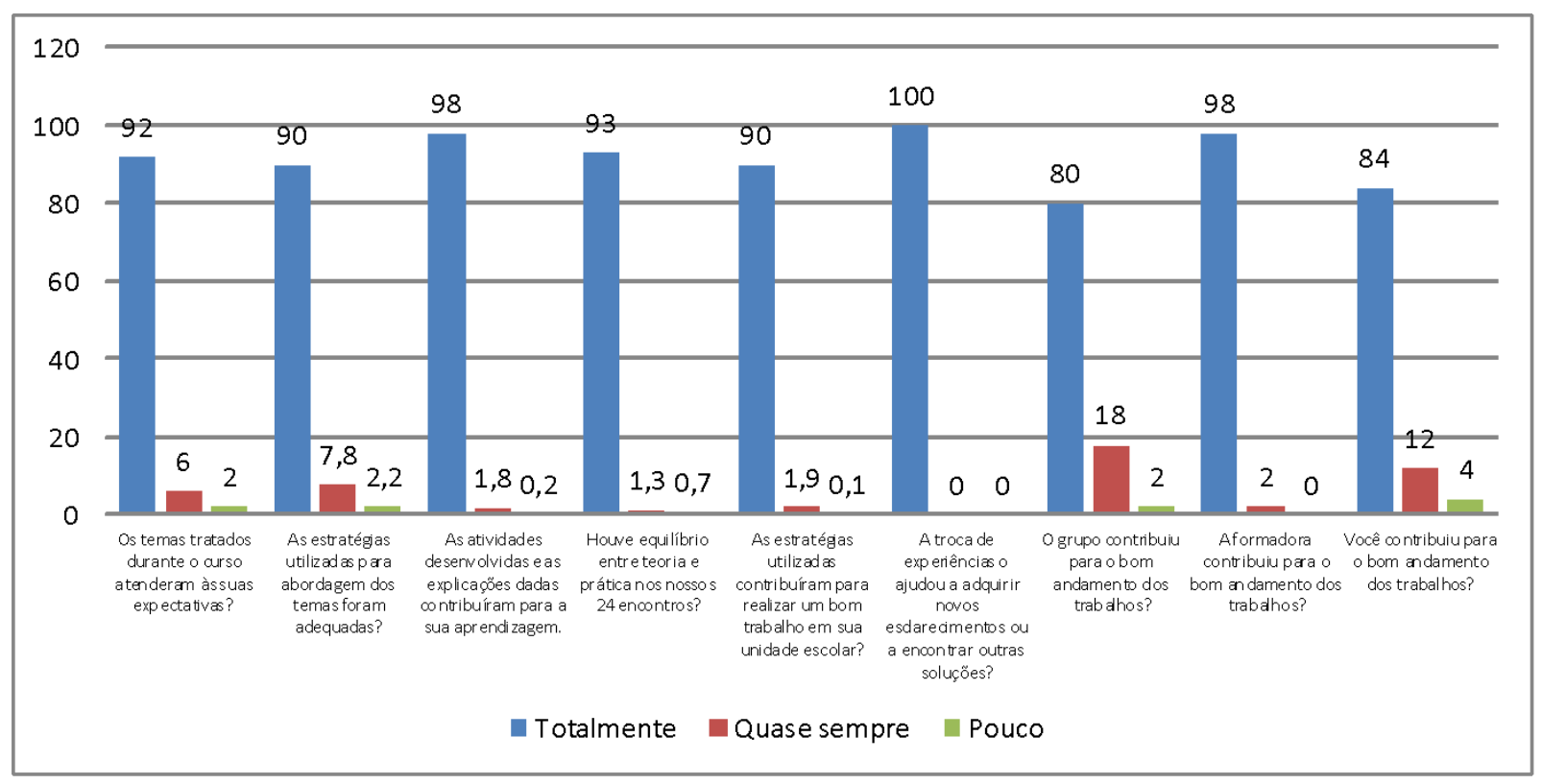

FONTE: Avaliação do curso - CEFOPE

Além das questões objetivas, a avaliação trouxe questões subjetivas, segue o consolidado das respostas:

- Temas (tópicos/assuntos) que despertaram maior interesse e que devem permanecer nas referências bibliográficas:

\section{SEMINÁRIO DE EDUCAÇÃO A DISTÂNCIA}

Diálogos sobre EaD e uso das TDIC na educação: regulamentação em tempos recentes 
Conceito de Gestão e Gestão Democrática, Liderança Educacional, Legislação, Planejamento Estratégico e como planejar Conselho de Classe.

- $\quad$ O número de horas diárias do curso foi:

\begin{tabular}{|c|c|c|}
\hline Insuficiente & Razoável & Excessivo \\
\hline $82 \%$ & $14,8 \%$ & $3,2 \%$ \\
\hline
\end{tabular}

- A avaliação dentro do curso tem um papel relevante para que as intervenções pedagógicas sejam efetivadas. Os instrumentos avaliativos utilizados foram adequados ou inadequados. Justifique.

A maioria dos gestores elogiaram as Práticas de Gestão e o Seminário, um percentual de 68\% considerou o Simulado inadequado.

- Utilize o espaço abaixo para apresentar, livremente, sugestões ou críticas que julgar necessárias, a respeito do curso concluído:

No geral o curso foi muito elogiado em relação ao cumprimento do cronograma, conteúdos coerentes e necessários para a prática gestora. Sugestões para que parte da formação fosse à distância.

- Classifique de um modo geral, o curso realizado como:

\begin{tabular}{|r|r|r|r|r|}
\hline Sofrível & \multicolumn{1}{|c|}{ Regular } & \multicolumn{1}{c|}{ Bom } & \multicolumn{1}{c|}{ Muito Bom } & Excelente \\
\hline $0,1 \%$ & $0,7 \%$ & $1,1 \%$ & $13,5 \%$ & $84,6 \%$ \\
\hline
\end{tabular}

A avaliação do curso destacou a importância de oferecer formação continuada que venha de encontro com os interesses, necessidades e anseios da realidade local, ampliando a visão das políticas educacionais desvencilhando das centralizações de ações formativas de caráter individualizado que reduz o impacto sobre a qualidade da educação. Ficou evidente também que esse formato coaduna com a proposição de políticas mais eficazes constantes nos estudos acadêmicos, com uma formação centrada na escola e abrangendo toda a equipe escolar, no cotidiano particular de sua espacialidade e realidade social. Carvalho $(1990,19-20)$ salienta que, 


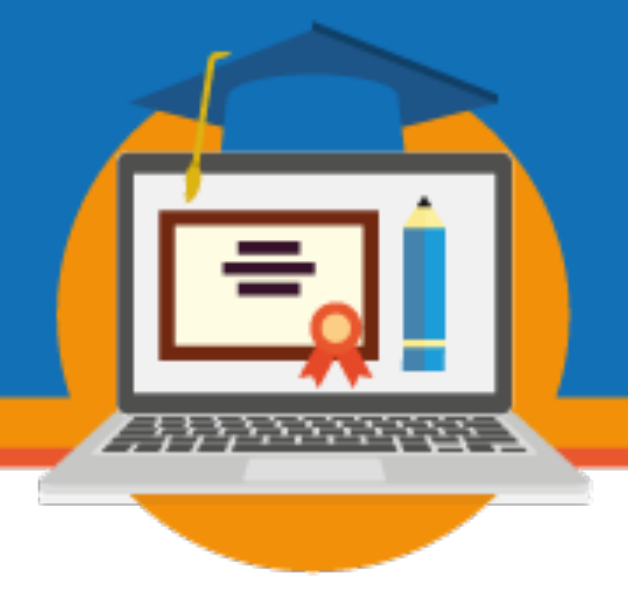

(...) os professores são agentes ativos na construção de sua própria prática (sem esquecer que estão em interação com os demais e imersos nas limitações da escola) e que adquirem e utilizam um corpo de conhecimento, às vezes chamado profissional ou destreza, em suas atividades docentes.

Nesse sentido, o saber profissional docente tem sido caracterizado como complexo, ativo, dinâmico e com várias faces. O conhecimento de si mesmo e de seu processo pessoal de aprendizagem profissional e da docência também tem sido identificado como componente do saber profissional do professor e dos demais profissionais de ensino.

De certa forma, o repensar a concepção da formação dos professores, que até pouco tempo objetivava a capacitação, através da transmissão do conhecimento, a fim de que "aprendessem" a atuar eficazmente na sala de aula, vem sendo substituído pela abordagem de analisar a prática que este professor vem desenvolvendo. Para tanto, é enfatizado a temática do saber docente e a busca de uma base de conhecimentos para os professores, considerando os saberes já construídos.

Nesse viés de pensamento teórico metodológico, o curso O Papel da Gestão Escolar nos Processos Educativos, possibilitou ao gestor complementar suas habilidades em gerir de forma interdisciplinar e interativa com a comunidade escolar.

Esse professor - gestor problematizou situações, mobilizou seu ambiente de trabalho e ensino, criou repertório e subsídios para analisar problemas e buscou solucionar situação de conflito por meio de projetos e novas práticas de pesquisa a partir de situações - problema.

Corrobora com esse pensamento a análise de Shôn (1997,87). Para ele: “(...) O desenvolvimento de uma prática reflexiva eficaz tem que integrar o contexto institucional". $\mathrm{O}$ professor necessita de tornar-se um navegador atento da burocracia diária. Não obstante:

(...) os responsáveis escolares que queiram encorajar os professores a tornarem-se profissionais reflexivos devem criar espaços de liberdade tranquila onde a reflexão seja possível. Estes são os dois lados da questão, aprender a ouvir os alunos e aprender a fazer da escola um lugar no qual seja possível ouvir alunos e devem ser olhados como inseparáveis (Op.Cit.).

Nessa perspectiva, o diretor constrói sua formação, fortalece e enriquece seu aprendizado. Para tanto, é importante “enxergar” o profissional da educação como sujeito e agente do processo transformador do fazer ensinar e fazer aprender. E isso tem sinalizado na 


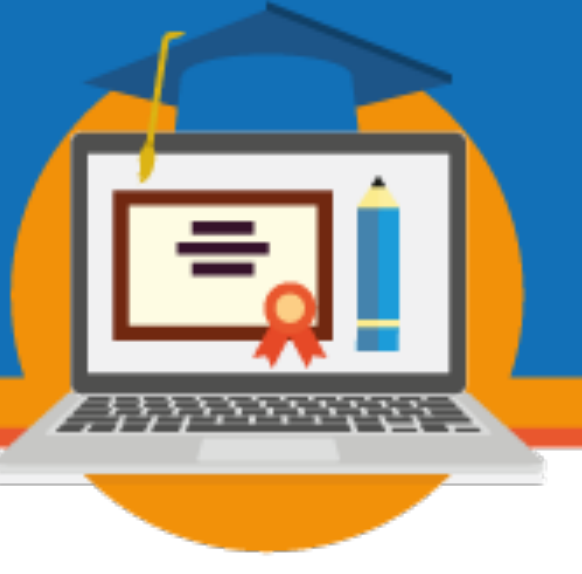

valorização do saber oriundo da experiência de cada docente. Essa é a proposta de Nóvoa (1997, p.26) no que tange o tempo e espaço vivido por aqueles que ensinam: "A troca de experiências e a partilha de saberes consolidam espaços de formação mútua, nos quais cada professor é chamado a desempenhar simultaneamente, o papel de formador e de formando".

\section{Perspectivas para a formação continuada biênio 2018-2019}

Analisando todo o caminho percorrido na Formação Continuada pelos diretores em Anápolis, observa-se que ainda há muito a avançar. Conforme as avaliações e discussões nos últimos quatro anos, o desafio é dar continuidade a formação de gestores educacionais das instituições escolares municipais de Anápolis, disponibilizando elementos teórico-práticos que viabilizem uma educação escolar básica com qualidade social, mas com a redução de encontros presenciais.

Para o alcance desta proposta se faz necessário a reelaboração do curso "O papel da gestão escolar nos processos educativos" contemplando momentos presenciais e momentos à distância, pretendendo assim democratizar ainda mais o acesso a novos espaços e ações, com vistas ao fortalecimento da escola pública como direito social inalienável.

Acredita-se que com a reestruturação do curso, com a adoção de processo formativo presencial articulado à educação à distância possibilitaremos, dentre outras: maior flexibilidade na organização e desenvolvimento dos estudos; fortalecimento da autonomia intelectual no processo formativo; acesso às novas tecnologias da informação e comunicação; interiorização dos processos formativos, garantindo o acesso daqueles que atuam em unidades escolares distantes; redução dos custos de formação a médio e longo prazo; a interatividade entre os formandos, facilitando o trabalho coletivo, e de formação de quadros para atuarem com EAD e sua institucionalização no tocante à formação continuada.

A referida reestruturação do curso tem por norte pedagógico garantir uma formação de qualidade socialmente referenciada, por meio da modalidade de educação a distância associada a presencial (ensino hibrido). Nessa direção, entende que o papel do professor formador é 


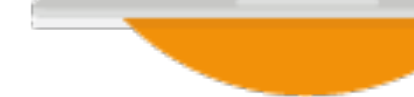

crucial para o bom andamento do curso, razão pela qual a dinâmica pedagógica enfatiza a ação docente em todos os momentos do curso optando por manutenção do professor na efetivação, no acompanhamento e no monitoramento e avaliação das ações de formação a serem desenvolvidas. A manutenção do papel do professor em detrimento a adoção da figura do tutor é um dos marcos políticos do curso. Entende-se, desse modo, que não se trata tão somente de adoção da nomenclatura, mas fundamentalmente da defesa da centralidade do papel do professor nos processos formativos presenciais e a distância. Tal compreensão retrata o papel da EAD sob a ótica de formação de qualidade que não prescinde do acompanhamento docente efetivo e de momentos presenciais de aprendizagem coletiva.

Ao reestruturar o curso inicialmente com momentos presenciais e a distância, pautamos na Lei de Diretrizes e Bases da Educação Nacional (Lei nº9. 394/96), em alguns de seus artigos específicos, estabelece o propósito de formação continuada de professores. $\mathrm{O}$ artigo 63 , inciso III, determina às instituições formadoras de educação manter programas de educação continuada para os profissionais da educação dos diversos níveis. O caput do artigo 80 dispõe que o "Poder Público incentivará o desenvolvimento e a veiculação de programas de ensino a distância, em todos os níveis e modalidades de ensino, e de educação continuada". O artigo 87, inciso III, das Disposições Transitórias, prevê que os municípios, e supletivamente o Estado e a União, deverão "realizar programas de capacitação para todos os professores em exercício, utilizando também, para isto, os recursos da educação à distância". Percebe-se que a LDB referenda a formação continuada, articulada com a EAD, sempre que necessária. Isso se deve ao fato de que o sistema presencial de educação formal apresenta-se insuficiente para atender as novas demandas sociais de formação, bem como de democratização do saber, neste início de século.

O Biênio de 2018-2019 será de grande desafio para todos, SOUSA; RAMALHO (2012) observa que são inúmeros os desafios da formação de gestores em serviço e com a utilização de metodologias que incluam a EAD, não só para os gestores, mas para toda a equipe técnica e pedagógica da Secretaria Municipal de Educação, CEFOPE, Conselho Municipal de Educação. 


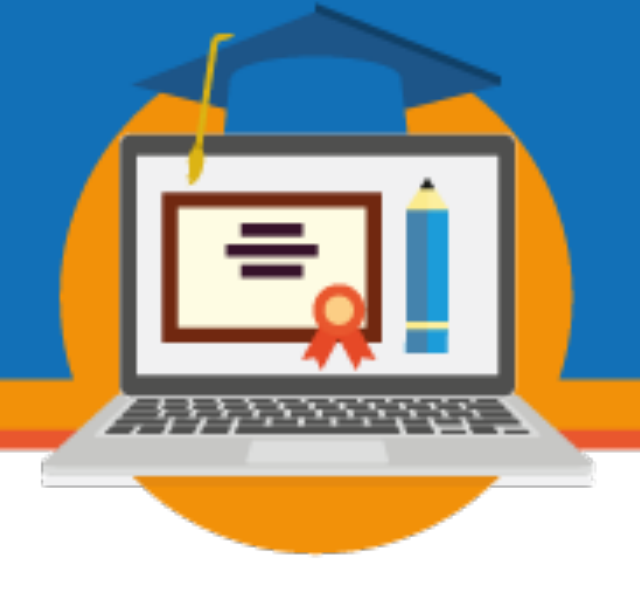

\section{Algumas considerações}

O curso evidenciou que é preciso possibilitar condições para aqueles que estão na gestão das unidades escolares estabeleçam a relação da formação oferecida com o saber-fazer no chão da escola, ou seja, que as discussões que foram promovidas nos encontros contemplaram as demandas pedagógicas e administrativas que emergem no espaço escolar, perceberam que a participação nesta ação formativa contribuiu para melhoraria da prática de gestão com o olhar pedagógico.

Outro ponto a destacar foi mudanças na prática gestora, maior autonomia na política do gestor, maior criticidade, condição esta indispensável para o exercício desta função, tanto na formação de cidadãos no âmbito da instituição escolar, bem como na articulação entre as vertentes políticas e as ações educacionais, valorizando e respeitando as decisões do coletivo escolar.

O CEFOPE que fez e faz parte desse processo por meio e visitas técnicas e orientações individuais. Considera-se que essa atividade de formação continuada para gestores ampara possíveis lacunas deixadas durante a formação acadêmica. Por conseguinte, cria condições desenvolvimento de competências e habilidades na dimensão do ser professor-gestor na esfera do o ensino, pesquisa e aprendizagem.

A formação continuada oferecida para os professores-gestores eleitos biênio de 20182019 trará muitos desafios principalmente em relação à implantação da modalidade à distância, mas também provocará muitos debates que possibilitaram a equipe CEFOPE ampliar a discussão e pensar em prováveis ofertas de outros cursos nesta modalidade.

O no uso das tecnologias nos processos de formação continuada, podemos dizer que a EAD é uma importante ferramenta no processo de formação continuada, não só por atender várias das demandas da sociedade da informação, ora vivenciada, mas também por propiciar

\section{SEMINÁRIO DE EDUCAÇÃO A DISTÂNCIA}

Diálogos sobre EaD e uso das TDIC na educação: regulamentação em tempos recentes 


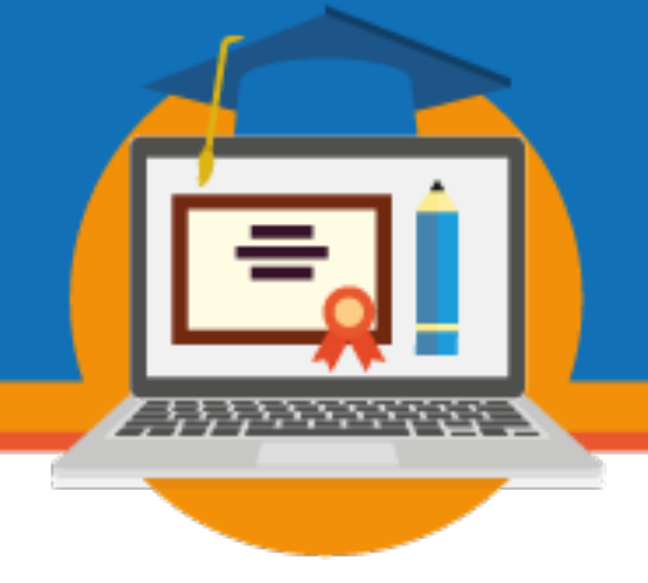

desafios no manuseio da plataforma (Moodle), gerando aprendizagens a serem integradas na gestão.

É importante garantir que todos os tenham o entendimento que o uso das tecnologias por si só não é a solução de todos os problemas, afinal conforme afirma Bueno; Gomes (2011), não podemos enxergar as TICs de forma mecânica, como se fossem algo ruim ou a solução de todos os males, pois as tecnologias por si só, tal como a formação continuada, não podem resolver todos os problemas que afetam a educação escolar, em virtude das contradições existentes na sociedade, e que se manifestam nas intenções e ideologias contidas nos discursos neoliberais, no contexto interno da escola, e nas as relações e atuação professor-gestor que está sendo "formado".

\section{Referências}

ANDRÉ, Marli Eliza Dalmazo Afonso. Estudo de caso em pesquisa e avaliação educacional. Líber livro Editora. Brasília, 2008.

BUENO, J. L. P.; GOMES, Marco A. de O. Uma análise Histórico-crítica da formação de Professores com tecnologias de informação e comunicação. Revista Cocar Belém, vol. 5, n. 10, p.53- 64 jul - dez, 2011.

BRASIL. Lei n 9.394, de 20 de dezembro de 1996. Estabelece as diretrizes e base da educação nacional. Brasília - Câmara dos Deputados, Edições Câmara, 2009.

CUNHA, M. e REGO, A. (1998), Liderança nas Organizações - teoria e prática, Universidade de Aveiro.

DOURADO, L. F. A escolha de dirigentes escolares: políticas e gestão da educação no Brasil. In: Gestão Democrática da Educação: atuais tendências, novos desafios. NauraCarapeto Ferreira (Org.). 3ed. Cortez.2001.(p. 59-76).

FREITAS, Luiz Carlos. Crítica da organização pedagógica e da didática. Campinas: Papirus, 1995. 


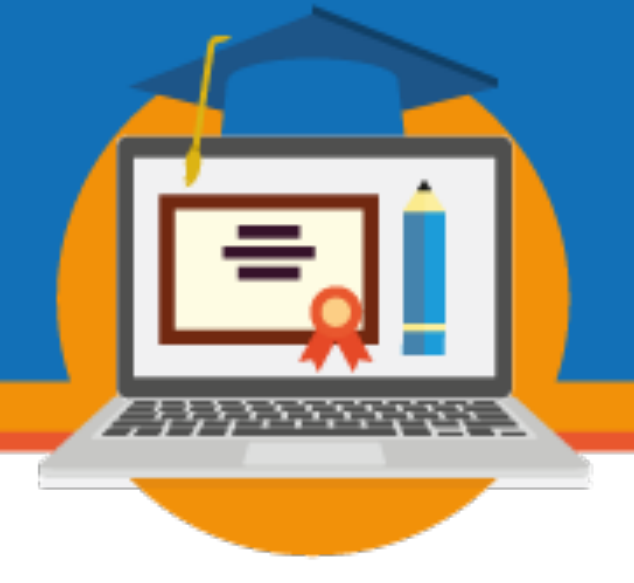

GAMBOA, Silvio Sánchez. Pesquisa em educação: métodos e epistemologias. $2^{\mathrm{a}}$ ed. Argos. Chapecó, 2012.

IACZINSKI SOBRINHO, Antônio. Elaboração e execução de projetos. Florianópolis: UFSC, 2010

LIBÂNEO, José Carlos. Os conceitos de organização, gestão, participação e de cultura organizacional. In: Organização e gestão da escola. Teoria e prática. 5 ed. Goiânia: Alternativa, 2004.

, José Carlos. Buscando a qualidade social do ensino. In: Organização e Gestão da Escola - Teoria e Prática. Goiânia: Editora Alternativa, 2001. (p. 53 - 60).

LÜCK, H. Gestão Educacional: uma questão paradigmática. $2^{\mathrm{a}}$ ed. Petrópolis: Vozes, 2006.

Dimensões de gestão escolar e suas competências. Curitiba: Editora Positiva, 2009.

NÓVOA, Antônio (Coord.). Os professores e sua formação. Lisboa: Dom Quixote, 1997.

PARO Vitor Henrique. Administração Escolar: Introdução Crítica- $16^{\mathrm{a}}$ ed. São Paulo: Cortez, 1986.

Ática, 2007.

Gestão Escolar, Democracia e Qualidade do Ensino. São Paulo:

. Educação Como Exercício do Poder - 2ª ed. São Paulo: Cortez, 2010.

ed. São Paulo: Xamã, 2003.

Eleição de Diretores: a Escola Pública Experimenta a Democracia. $2^{\mathrm{a}}$ . Crítica da Estrutura da Escola. São Paulo: Cortez, 2011.

TARDIF, Maurice. Saberes docentes e formação profissional. Petrópolis/RJ: Vozes, 2002.

SCHÖN, Donald. Os professores e sua formação. In: NÓVOA, Antônio (Coord.). Lisboa: Dom Quixote, 1997.

SOUSA, A. da S. Q.; RAMALHO, B. L. Politicas de Formação de Professores no Brasil e a modalidade a distância: pontos para reflexão. IN Revista Exitus. UFOPA Belém, PA: Editora destaque-se - ano 2, n. 1, 2012. 


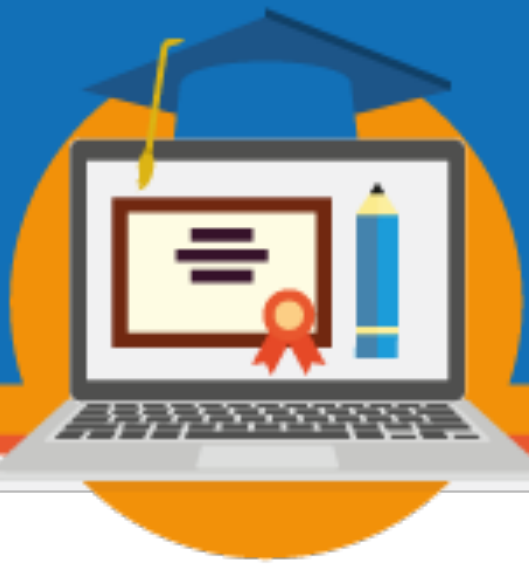

VYGOTSKY, Lev Semenovitch. Psicologia Pedagógica. Trad. Paulo Bezerra. 3 ed. São Paulo: Martins Fontes, 2010.

YOUNG, Michael. Para que servem as escolas? Educ.Soc., Campinas, v. 28, $\mathrm{n}^{\circ}$ 101, dez. 2007. 